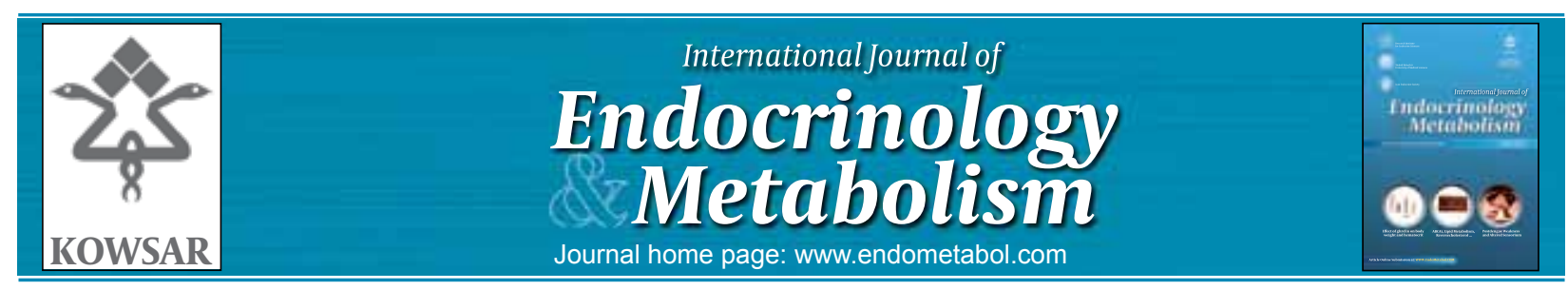

\title{
Effect of Proteolysis in Erythrocyte Damage of Diabetic Complications
}

\author{
Ganapathy Saravanan ${ }^{1^{*}}$ \\ ${ }^{1}$ Department of Biochemistry, centre for Biological Science, K.S.R College of Arts and Science, Tamil Nadu, India
}

A R T I C L E I N F O

Article Type:

Letter to Editor

Article history:

Received: 30 Jul 2010

Revised: 07 Aug 2010

Accepted: 01 Jan 2011

Keywords:

Oxidative stress

Erythrocyte damage

Diabetic complication

\section{Dear editor:}

Diabetes is a complex metabolic disorder characterized by defects in the body's ability to control glucose and insulin homeostasis, and it is estimated that in the future, the annual incidence rate of diabetes will continue to increase worldwide. Currently, it is believed that various complications of diabetes mellitus result from oxidative stress wherein increased free radical production is coupled with low levels of cellular antioxidants (1). Because the human erythrocyte plays a role as an $\mathrm{O} 2$ and $\mathrm{CO} 2$ transporter, it is constantly exposed to reactive oxygen species (ROS) and oxidative stress. Oxidative stress occurs in cells or tissues when ROS concentration exceeds antioxidant concentration (2). Oxidant damage to proteins makes them more vulnerable to proteolytic degradation by enzymes that recognize modifications like conformational changes and fragmentation. A combination of increased oxidant production and decreased antioxidant levels in the erythrocytes in a diabetes mellitus patient contributes to the vulnerability of glycated hemoglobin to oxidant damage and subsequent proteolytic degradation. Oxidant-damaged hemoglobin is

\footnotetext{
* Corresponding author at: Ganapathy Saravanan, Department of Biochemistry, Centre for Biological Science, K.S.R College of Arts and Science, Thokkavadi, Tiruchengode, 637215, Tamil Nadu, India. Tel: +91-9843954422, E-mail: saravana_bioc@rediffmail.com

DOI: 10.5812/Kowsar.1726913X.2068

Copyright $\odot 2011$, Iran Endocrine Society, Published by Kowsar M.P.Co. All rights reserved.
}

- Please cite this paper as:

Saravanan G. Effect of Proteolysis in Erythrocyte Damage of Diabetic Complications. Int J Endocriol Metab. 2011; 9(1): 276-7. DOI: 10.5812/Kowsar.1726913X.2068

๑ 2011 Kowsar M.P.Co. All rights reserved.

a potential substrate for certain proteolytic enzymes in reticulocytes and erythrocytes (3). Moreover, this vulnerability of erythrocytes in diabetic patients may lead to a loss of red blood cell (RBC) function and increased rate of apoptosis of erythrocytes and the removal of erythrocytes from circulation through macrophage phagocytosis. First, we would like to congratulate the authors, Varashree and Gopalskrishna, for their recently published study in the International Journal of Endocrinology and Metabolism; their study highlighted an important complication of diabetes mellitus and provided new evidence for proteolytic degradation in the erythrocytes of diabetic patients (4).

In the Discussion section, the authors contemplate that oxidative stress might account for the alteration in protein structure and function in the erythrocytes of diabetic patients. We agree with the authors' findings that oxidative stress is the factor that mediates proteolytic degradation in the erythrocytes of diabetic patients. In this manuscript, it is well outlined how oxidative stress fits their current understanding of proteolytic degradation in erythrocytes, and how it might explain the observations done by Raghothama and Rao (5). These authors pointed out that the erythrocytes in diabetic patients are more susceptible to oxidant-mediated damage, and hence, the antioxidant defenses are decreased in the RBCs of diabetic patients. Glucose oxidation in the presence of transition metals could result in excessive generation of ROS, which could in turn affect the biomembrane struc- 
ture and function by mediating lipid peroxidation (6). Enhanced malondialdehyde (MDA) levels observed in the erythrocytes of diabetic patients can, therefore, be attributed to increased biomembrane lipid peroxidation; this lipid peroxidation also contributes to variations in the antioxidant levels (7). Erythrocytes are physiologically well protected against ROS by abundant proteolytic enzymes, which are considered the second line of defense against oxidative damage; further, the proteolytic enzymes play a crucial role in preventing the damage caused by modified proteins. A multicatalytic proteolytic complex appears to be responsible for the degradation of oxidized intracellular proteins in erythrocytes (2). In this article, the authors have also discussed the role of serine protease activity after the oxidative modification of the membranes. Fujino et al. (8) have shown the presence of an $80-\mathrm{kDa}$ serine protease in oxidized erythrocyte membranes that preferentially degrades oxidized proteins. Additionally, a protein named oxidized protein hydrolase (OPH) functions as a secondary defense system by removing oxidized protein aggregates (8). Moreover, protein degradation pathways never require any energy source. Hence, further investigation is required to elucidate the role played by various enzymes in controlling diabetes.

\section{Financial Disclosure}

None declared.

\section{References}

1. Saravanan G, Ponmurugan P. Ameliorative potential of S-allyl cysteine on oxidative stress in STZ induced diabetic rats. Chem Biol Interact. 2011;189(1-2):100-6.

2. Fujino T, Tada T, Hosaka T, Beppu M, Kikugawa K. Presence of oxidized protein hydrolase in human cell lines, rat tissues, and human/rat plasma. J Biochem. 2000;127(2):307-13.

3. Hunt JV, Bottoms MA, Mitchinson MJ. Oxidative alterations in the experimental glycation model of diabetes mellitus are due to protein-glucose adduct oxidation. Some fundamental differences in proposed mechanisms of glucose oxidation and oxidant production. Biochem J.1993;291(Pt 2):529.

4. Varashree BS, Gopalakrishna BP. Oxidative stress and proteolytic activity in erythrocytes of diabetic patients. Int J Endocrinol Metab. 2010;8(2):90-3.

5. Raghothama C, Rao P. Increased proteolysis of oxidatively damaged hemoglobin in erythrocyte lysates in diabetes mellitus. Clin Chim Acta. 1994;225(1):65-70.

6. Hunt JV, Smith CC, Wolff SP. Autoxidative glycosylation and possible involvement of peroxides and free radicals in LDL modification by glucose. Diabetes. 1990;39(11):1420-4.

7. Pavana P, Sethupathy S, Manoharan S. Antihyperglycemic and antilipidperoxidative effects ofTephrosia purpurea seed extract in streptozotocin induced diabetic rats. Indian J Clin Biochem. 2007;22(1):77-83.

8. Fujino T, Tada T, Beppu M, Kikugawa K. Purification and characterization of a serine protease in erythrocyte cytosol that is adherent to oxidized membranes and preferentially degrades proteins modified by oxidation and glycation. $J$ biochem. 1998;124(6):1077. 